\title{
Fungal Infections in Liver Transplant Recipients
}

\author{
Michael Scolarici ${ }^{1}$, Margaret Jorgenson ${ }^{2}$, Christopher Saddler ${ }^{1}$ and Jeannina Smith ${ }^{1, *}$ \\ 1 Department of Medicine, University of Wisconsin, Madison, WI 53792, USA; MScolarici@uwhealth.org (M.S.); \\ csaddler@uwhealth.org (C.S.) \\ 2 Department of Pharmacy, University of Wisconsin, Madison, WI 53792, USA; MJorgenson@uwhealth.org \\ * Correspondence: jsmith@medicine.wisc.edu
}

check for

updates

Citation: Scolarici, M.; Jorgenson, M.; Saddler, C.; Smith, J. Fungal Infections in Liver Transplant Recipients. J. Fungi 2021, 7, 524. https://doi.org/10.3390/jof7070524

Academic Editor: Marisa H. Miceli

Received: 22 April 2021

Accepted: 21 June 2021

Published: 29 June 2021

Publisher's Note: MDPI stays neutral with regard to jurisdictional claims in published maps and institutional affiliations.

Copyright: (C) 2021 by the authors. Licensee MDPI, Basel, Switzerland. This article is an open access article distributed under the terms and conditions of the Creative Commons Attribution (CC BY) license (https:/ / creativecommons.org/licenses/by/ $4.0 /)$.
Abstract: Invasive fungal infections (IFIs) are one of the most feared complications associated with liver transplantation, with high rates of morbidity and mortality. We discuss the most common invasive fungal infections in the setting of liver transplant, including Candida, Aspergillus, and Cryptococcal infections, and some less frequent but devastating mold infections. Further, we evaluate the use of prophylaxis to prevent invasive fungal infection in this population as a promising mechanism to reduce risks to patients after liver transplant.

Keywords: liver transplant; invasive fungal infection; candidiasis; cryptococcosis; Aspergillus

\section{Introduction}

Patients with liver transplants are at enhanced risk of invasive fungal infections (IFIs), which are feared complications with high rates of morbidity and mortality. These infections are common with the incidence of IFIs between $4 \%$ and $40 \%$ in all liver transplant recipients [1,2]. Underlying liver disease is associated with increased risk of infection from several fungal pathogens, including Candida and Cryptococcal species, which, in addition to exogenous immunosuppression after transplant, result in unique epidemiology of fungal infections in this population [3]. Patients with liver transplant experience significant morbidity and mortality from IFIs [4,5]. The mortality of IFIs in this population is very high, ranging from $25 \%$ to $67 \%$ [5]. Here we review the literature regarding IFIs in liver transplant recipients with a focus on the most common and most devastating pathogens.

\section{Candida Species}

\subsection{Epidemiology}

Candida species are common organisms of pathogenic potential that can colonize the gastrointestinal tract, genitourinary tract, and skin. The major pathogenic species are C. albicans, C. glabrata, C. parapsilosis, C. tropicalis, and C. krusei. Additionally, C. auris is a concerning emerging pathogen that has significant baseline resistance and potential for extensive resistance. The overall invasive fungal infection (IFI) rate post-liver transplant at 1 year is $1.8 \%$, reaching $2.9 \%$ at 5 years and $5 \%$ by 10 years [6]. Of these IFIs, Candida infections represent the vast majority, causing $68-93 \%$ of post-liver-transplant IFIs $[7,8]$. Over time, there has been a trend toward infection with non-albicans species. For instance, a Spanish cohort examining candidemia over time in solid organ transplant recipients (SOTRs), comparing 2010-2011 with 2016-2018, showed an increase in C. glabrata over time from $18.8 \%$ to $30.4 \%$ and a decrease in C. albicans cases over that period [9]. Further, there has been suggestion of higher mortality with non-albicans species. Prior azole use was linked to glabrata isolation [10]. Finally, the emerging highly drug-resistant C. auris has been reported in liver transplant recipients, including by Theodoropoulos et al., which could threaten both prophylaxis and treatment of invasive candidiasis (IC) in patients with liver transplants [11].

Risk factors for IC in the general population include older age, broad-spectrum antibiotics, central venous catheterization, parenteral nutrition, prolonged neutropenia, 
prolonged ICU stay, diabetes, renal replacement, and Candida colonization [12]. Risk factors specific to liver transplant recipients include anastomotic leak, repeat laparotomy, and choledochojejunostomy [13-15]. Factors identified in SOTRs overall include acute renal failure, recent CMV, graft failure, early re-exploration, and Candida colonization [16].

\subsection{Clinical Manifestations}

Clinical manifestations are well described elsewhere, but briefly range from asymptomatic colonization to life-threatening infection. The most common forms of invasive disease in liver transplant recipients are candidemia and intra-abdominal infection. It is important to recognize that early post-transplant signs and symptoms of deep Candida infection can be nonspecific, and a high index of suspicion is needed.

\subsection{Diagnosis}

The critical step in IC diagnosis is consideration. The gold standard remains culture from a sterile site or identification by histopathology on a tissue sample.

Traditional blood cultures still have significant limitations. In a study involving nonliver-transplant recipients, the sensitivity of blood cultures for the detection of IC was only $\sim 50 \%$ [17], and cultures are often negative despite deep-seated infections, such as intra-abdominal infections common after liver transplantation. Other means of detection are necessary.

Beta-D-glucan (BDG) is a component of the fungal cell wall of Candida species, as well as other fungi, that can be detected in serum and may be elevated in the setting of Candida infection. However, its use is limited by numerous other causes of positivity, such as infection with Aspergillus and Pneumocystis species, exposure to cellulose membranes for dialysis, platelet infusion with leukocyte-removing filters, immunoglobins, albumin, certain IV antibiotics, bacteremia, surgical gauze containing glucan, and severe mucositis [18]. Sensitivity ranges from $70 \%$ to $93 \%$, and specificity from $65 \%$ to $87 \%$ overall; in a study of liver transplant recipients, two sequential positive BDGs plus evidence of Candida colonization had a sensitivity of $83 \%$, a specificity of $89 \%$, and a negative predictive value of $97.6 \%$ for IC [19]. This particularly demonstrates the strong negative predictive value of BDG when considering Candida, but understanding its test characteristics is critical for appropriate use.

The T2 Candida assay has also emerged as a non-culture-based diagnostic test performed directly on whole blood to detect the five most common pathogenic Candida species (C. albicans, C. glabrata, C. parapsilosis, C. tropicalis, and C. krusei) with clinical trial performance of $89-91 \%$ sensitivity and $99 \%$ specificity. The most attractive feature of this test is that results are available in $3-5 \mathrm{~h}$ vs. days with traditional culture. These characteristics have been utilized to improve antifungal stewardship and can reduce time to effective therapy. Currently, it does not detect the emerging highly drug-resistant $C$. auris, but this is in development with promising results [20]. This test is not yet widely available. use [21].

PCR-based assays for IC show promise but are not yet readily available for clinical

Overall, a high index of suspicion is required for the diagnosis of IC, and often a combination of testing approaches is required for adequate evaluation.

Susceptibility testing on Candida species is increasingly important, as antifungal pressure is common, and infections with non-albicans species are becoming more frequent. Susceptibility testing should be performed in all clinically significant isolates, such as bloodstream or deep cultures, particularly in the setting of prior azole exposure, C. glabrata, C. parapsilosis, and C. auris, as recommended by the Infectious Disease Community of Practice in the American Society of Transplantation (ID AST COP) [22].

\subsection{Treatment}

The mainstays of therapy are early consideration of Candida infection, to allow for prompt initiation of therapy, and rapid attainment of adequate source control. Given the 
frequency of non-albicans species, perioperative azole exposure, and nosocomial contact associated with liver transplantation, empiric therapy should typically be an echinocandin. Stepping down to alternative therapy, such as an azole, should be guided by species identification and susceptibility testing. Therapy should follow the Infectious Disease Society of America (IDSA) 2016 guidelines endorsed by ID AST COP [22,23].

\subsection{Outcomes}

Despite ongoing efforts toward prevention and improved management of fungal infection, IC still has significant effects on graft function, morbidity, and mortality posttransplant with reports of 90-day mortality of $26 \%$ [7].

Overall, Candida infections are the most common post-liver-transplant IFIs, have significant risk of harm, and require a high index of suspicion, rapid diagnostic evaluation which is often multimodal, and aggressive management, including maximization of source control and early appropriate antifungal therapy.

\section{Aspergillus Species}

\subsection{Epidemiology}

Patients with liver transplants are at risk of invasive infections with Aspergillus species. The incidence of invasive Aspergillus infection ranges from 1\% to $9 \%$ in patients after liver transplantation $[2,24,25]$. This rate is impacted by several well-defined risk factors, including prolonged surgical time, massive intraoperative transfusion requirement, retransplantation, steroid-resistant rejection, acute kidney injury, cytomegalovirus (CMV) infection, diabetes, and use of broad-spectrum antibiotics [26,27].

\subsection{Pathogenesis and Clinical Manifestations}

Aspergillus species are ubiquitous saprophytic fungi found in the environment, particularly in areas of decaying vegetation. Over 200 Aspergillus species have been identified. In the environment, the fungi produce conidia, which can disperse widely in the air. When they are inhaled, they can cause pulmonary infection ranging from a noninvasive fungal ball to invasion and dissemination depending on a variety of host factors. A variety of Aspergillus species have been associated with infection in liver transplant recipients. The most common infecting Aspergillus species are Aspergillus fumigatus (73\%), Aspergillus flavus (14\%), and Aspergillus terreus (8\%) [24], but rare species are also reported to cause invasive infections with significant morbidity [28].

The majority of invasive Aspergillus infections in liver transplant recipients are pulmonary, as the most common exposure mechanism is inhalation of the mold. Dissemination with widespread disease, including involvement of the heart, eyes, muscles, thyroid, and central nervous system (CNS), is well documented [29,30]. Isolated invasive fungal sinusitis from aspergillosis is also reported [31].

\subsection{Diagnosis}

Timely diagnosis of invasive Aspergillus infection in liver transplant recipients requires a high index of suspicion. Patients who develop fever, respiratory symptoms, or symptoms of disseminated infection should be evaluated with advanced chest imaging, such as computed tomography (CT) [32]. Plain radiographs may give falsely-negative results and should not be used to exclude pulmonary involvement. Focal symptoms elsewhere, such as the sinuses, should also have appropriate imaging modalities, such as dedicated sinus CT. Characteristic findings of invasive pulmonary aspergillosis (IPA) on chest CT include ground-glass opacities, cavities, and nodules with or without halo [33]. In a study of patients with proven or probable IPA after liver transplant, three main radiological findings were identified: nodules with or without a halo sign, masses, and consolidations in a patchy pattern. A tree-in-bud pattern was seen in $12 \%(3 / 25)$ of patients. The halo sign was seen in $80 \%$ of liver transplant recipients within 1 week after the onset of symptoms. The hypodense sign was observed in large nodules or masses, which then became cavitary 
within a month after the onset of symptoms in almost 70\% [33]. Sinus imaging may reveal invasion of local structures and/or mycetoma [34]. It is not possible to distinguish the species causing invasive fungal sinusitis, and rhinocerebral mucormycosis would also be in the differential of these findings. Diagnostic material should be obtained, directed by imaging findings.

Serological markers can be used to augment diagnostic capabilities and should be paired with imaging and culture for the diagnosis of invasive infection. Serum and bronchoalveolar lavage (BAL) galactomannans (GM) are recommended as accurate markers for the diagnosis of invasive Aspergillus infections [32]. A GM index of 0.5 or higher is considered positive [35]. BAL GM has been shown to be even more sensitive and provide an earlier positive result than serum testing or traditional culture methods on BAL fluid in solid organ transplant recipients [36]. BDG is less specific in the liver transplant population, likely because of the presence of factors associated with false-positive testing as listed above. In one study of liver transplant patients on antifungal prophylaxis, a baseline of $50 \%$ of the patients tested positive for BDG. In this study, the sensitivity, specificity, positive predictive value (PPV), and negative predictive value (NPV) of BDG for IFI were $75 \%$ (95\% CI: 65-83), 65\% (62-68), 17\% (13-21), and 96\% (94-97), respectively. The authors proposed that raising the cutoff for positivity to $80 \mathrm{pg} / \mathrm{mL}$ enhanced the specificity without sacrificing the sensitivity [37]. In summary, the BDG has good negative predictive values, but the high rate of false-positive tests suggests that it should be interpreted in the complete clinical context $[32,35,37]$.

\subsection{Treatment}

Modern treatment regimens for invasive Aspergillus infections are associated with reduced mortality overall, and in particular, the introduction of triazole therapy has dramatically improved outcomes [24]. One of the challenges of treatment of invasive fungal infection in liver transplant recipients is that nearly all available antifungal drugs have some risk of hepatotoxicity. This risk is compounded by the concomitant use of interacting medications, specifically immunosuppressive therapy. Before 2000, the vast majority of patients with IPA after liver transplant were treated with amphotericin B. After the introduction of voriconazole, this agent quickly became the drug of choice. Combination therapy, such as adding an echinocandin to an azole, is rarely used but may be associated with improved outcomes in very select cases [24].

\subsection{Outcomes}

Invasive Aspergillus infection remains morbid in liver transplant recipients. In a 2015 study, overall mortality was $66 \%$, with a 1-year overall probability of survival of only $35 \%$. The use of modern triazole therapy, specifically voriconazole, was associated with improved outcomes [24]. Risks of poor outcome of Aspergillus infection included short time from transplant to diagnosis (less than 25 days), renal failure and need for dialysis especially, and multiorgan involvement [24].

\section{Cryptococcal Species}

\subsection{Epidemiology}

Cryptococcus species are ubiquitous fungi found worldwide in soil and bird droppings [38]. Several species are clinically significant, including Cryptococcus neoformans and Cryptococcus gattii, which are now divided into separate species. Both species cause invasive disease in humans, although their manifestations have some important differences. C. neoformans can cause infection in both immunocompromised and apparently immunocompetent patients but tends to behave more like a true opportunist [38]. C. gattii, on the other hand, has been associated with cryptococcosis in immunocompetent persons in subtropical regions and more recently the northwest coast of North America, specifically near Vancouver Island and China [39]. When SOTRs become infected with C. gattii, they are more likely to have disseminated infection, and the incidence of CNS disease and mortality 
is much higher [40]. Cryptococcal infection is the third most common invasive fungal infection in recipients of solid organ transplant [41] with an overall incidence of $0.3-5 \%[7,42]$ and is associated with significant morbidity and mortality. A majority of patients (54-62\%) with cryptococcosis after solid organ transplant develop CNS disease [43].

\subsection{Pathogenesis and Clinical Manifestations}

Cryptococcal disease is typically associated with inhalation of poorly encapsulated yeast cells or basidiospores from the environment. These establish infection in the lungs, which is often asymptomatic, even in immunocompromised patients. From there, cryptococcus can travel throughout the body, including the CNS, by direct invasion but also in part because they are carried by macrophages in a "Trojan horse"-like mechanism into protected sites $[38,44]$. Patients with end-stage liver disease (ESLD) are at enhanced risk of developing Cryptococcal disease both pre- and post-transplant as a result of physiological changes induced by ESLD, including impaired cell-mediated immunity, phagocyte dysfunction, complement deficiency, and hypogammaglobulinemia [4,45]. Dissemination is much more likely to occur in patients with deficient cell-mediated immunity. Among SOTRs, the risk of developing disseminated disease was significantly higher for liver transplant recipients (adjusted hazard ratio (HR), 6.65; $p=0.048$ ) in [46].

Cryptococcus can also occasionally be inoculated directly into the skin, causing local infection [47]. The majority of post-transplant Cryptococcus infections are from reactivation of latent infection, but acquisition of the fungi after transplant is also reported, including from pet birds [48]. There are also cases of donor origin, but this appears to be rare [49].

Invasive Cryptococcus infection may cause lung masses, pneumonia, and fungemia and has a predilection for CNS infection, including mass lesions and meningitis. For that reason, Cryptococcal disease should be considered in liver transplant recipients with fever, headache, subacute mental status changes, or mass lesions in the lungs or CNS [41].

\subsection{Diagnosis}

Diagnosis of Cryptococcal infection is typically made by Cryptococcal antigen (CrAg) assay from serum and cerebrospinal fluid (CSF) or biopsy with fungal stains and cultures [41]. Several assays are available for Cryptococcal antigen testing, including latex agglutination (LA), enzyme immunoassay (EIA), and lateral flow Cryptococcal antigen assay (LFA). The analytic sensitivity of the LFA was demonstrated to be consistently superior to those of the LA or EIA across all serotypes in [50].

Serum Cryptococcal antigen is positive in $88-91 \%$ cases of CNS disease [43]; however, in transplant recipients CNS disease may be present even in the absence of detectable antigenemia. CNS antigen testing nearly always yields a positive result in CNS infection. Lumbar puncture should be performed in all transplant recipients with Cryptococcal infection to evaluate for CNS disease. Opening pressure should always be obtained as management of elevated pressure is critical for good outcomes. Characteristic CSF findings include mild pleocytosis ( 20 to 200 cells $/ \mu \mathrm{L}$ ), mildly elevated protein, and hypoglycorrhachia. The absence of pleocytosis and chemical changes does not rule out CNS involvement, however.

\subsection{Treatment}

New guidelines for the treatment of Cryptococcal infections after solid organ transplant has just been released by the ID AST COP [41]. These guidelines are generally in agreement with the IDSA guidelines [37]. Patients with CNS infection, including cryptococcomas and meningitis, and moderate to severe pulmonary infections should be treated with liposomal amphotericin B, plus flucytosine. Management is often complicated by acute kidney injury and cytopenias, so therapeutic drug monitoring (TDM) of the flucytosine is a recommended guideline [37]. If TDM cannot be performed, careful monitoring of renal function and cell counts is important to identify toxicity. After induction, most patients may be treated with prolonged fluconazole maintenance therapy. Patients with mild pulmonary disease do 
not need induction therapy and may be treated safely with fluconazole throughout the treatment course [41,51].

Infections with C. gattii may be associated with higher fluconazole MICs [40]. These infections may require other azoles for step-down therapy based on antifungal susceptibility testing, and optimal therapy in this setting is not well defined.

Reduction of immunosuppression may be helpful in controlling the infection, but rapid reduction in immunosuppression has also been associated with immune reconstitution inflammatory syndrome (IRIS) [52]. This may mimic worsening infection, but since it is treated with anti-inflammatories rather than anti-infectives, it is important to consider whether patients suddenly worsen despite negative cultures. The treatments of IRIS after Cryptococcal infection are typically steroids, but newer agents, such as adalimumab, have been used successfully in a refractory case [53]. New guidelines for the treatment of Cryptococcal infections after solid organ transplant have just been released [41].

\subsection{Outcomes}

The overall 90-day mortality from Cryptococcal infection after solid organ transplant was $14 \%$ and was higher among patients with renal failure, abnormal mental status, fungemia, and disseminated disease [46].

Recent data suggest that Cryptococcal infection should not be considered an absolute contraindication to proceeding with liver transplantation, but that this decision should be made cautiously as mortality is high in this patient population [4].

\section{Other Opportunistic Fungi: Scedosporium, Mucormycetes, Fusarium}

\subsection{Epidemiology}

Invasive molds, such as Scedosporium, Mucomycetes, and Fusarium species, are uncommon after liver transplantation given the lower net immunosuppressive burden when compared with hematopoietic stem cell transplantation (HSCT) or other solid organ allograft subtypes. However, incidence is increasing, likely due to the availability of more potent immunosuppression along with the use of newer antifungal agents for prophylaxis of Candida infection after transplantation [54]. Indeed, Scedosporium species are increasingly important pathogens in the immunocompromised host, accounting for $25 \%$ of non-Aspergillus mold infections in transplant recipients [55]. The incidence of mucormycosis in liver transplant recipients has been estimated to be $4-16$ per 1000 patients [56,57]. Fusarium typically manifests as a local infection after solid organ transplant with disseminated fusariosis being exceedingly rare. In one review of the literature, only six cases were reported between 1979 and 2020 [58].

\subsection{Pathogenesis, Clinical Manifestations, and Diagnosis: Scedosporium}

Scedosporium is a soil-dwelling saprophyte. It can also be found in water bodies that have been polluted by environmental contaminants or sewage. There are three pathogenic species that result in human infection, including Scedosporium apiospermum and its teleomorphs Pseudallescheria boydii, Lomentospora prolificans (formally Scedosporium prolificans), and Scedosporium aurantiacum [59]. When cultured on standard culture media, Scedosporium species appear as branching septate hyphae. Infection can occur in varying degrees of severity and typically manifests as pneumonia. Infection can also involve sinuses, bones, joints, eyes, and the CNS. The mode of transmission is typically considered to be spore inhalation; however, disseminated invasive infection after near drowning can occur with Scedosporium species being the most common cause of fungal infection in this setting [60]. Additionally, donor-derived infection of the recipient after near drowning of the donor has been described [61].

\section{Treatment and Outcomes: Scedosporium}

Treatment of Scedosporium species is challenging. It is intrinsically resistant to amphotericin deoxycholate and all liposomal formulations. S. apiospermum/P. boydii may 
respond to antifungal triazoles, particularly voriconazole, which has the best in vitro profile with MICs of 0.12 to $0.5 \mathrm{mcg} / \mathrm{mL}$ in clinical isolates obtained from lung transplant recipients [62]. Due to poor efficacy of single agents, synergy has been explored, with combinations of terbinafine and micafungin with voriconazole, resulting in the best in vitro responses [61,63]. Granulocyte-macrophage colony-stimulating factors have also been used to improve response, given reliance on innate immunity, particularly the role of polymorphonuclear cells. Infections caused by L. prolificans do not usually respond to antifungal therapy alone and often require surgery and reversal of immunosuppression [59]. Outcomes in transplant recipients are poor, with mortality estimated to be $59 \%$ across species, and mortality attributed to L. prolificans and S. aurantiacum $>70 \%$ [61].

\subsection{Pathogenesis, Clinical Manifestations, and Diagnosis: Mucormycetes}

Mucormycetes are a class of ubiquitous soil-dwelling saprophytic fungi that are found in decaying plants or animal matter. Most often the isolated genera include Rhizopus, Rhizomucor, Mucor, and Absidia. On tissue histopathology, they appear as broad, ribbonlike, sparsely septate hyphae with right angular branching [64]. Although more commonly described in the setting of neutropenia or hyperglycemia related to diabetic disease, high steroid burden, as used to treat rejection, is a postulated risk factor for disease in SOTRs $[65,66]$. Manifestations range from local cutaneous infection to hematogenous dissemination, with the most common presentation being rhinosinusitis, with or without rhinocerebral extension, followed by pulmonary mucormycosis [65].

\section{Treatment and Outcomes: Mucormycetes}

Treatment requires a multipronged approach with immunosuppressive reduction, surgical invention, systemic amphotericin $B$, and even local irrigation with amphotericin B $[65,67]$. In one report, mortality was $50 \%$ for any manifestation and was not different across allograft subtypes [65]. Prognoses associated with rhinocerebral and disseminated diseases were poor at $93.3 \%$ and $100 \%$, respectively [65]. Survival was improved in patients who had aggressive reduction or discontinuation of immunosuppression compared with those without a change in their regimen (69.5\% vs. $46.1 \%, p=0.05)$ [65].

\subsection{Pathogenesis, Clinical Manifestations, and Diagnosis: Fusarium}

Fusarium species are also common soil-dwelling saprophytes. Human pathogenic species are mainly limited to the F. solani complex (Neocosmospora species), but also include F. oxysporum, F. verticillioides, and F. proliferatum [68]. Local fusarial infections can occur in both immunocompetent and immunocompromised hosts and are typically the result of trauma. Disseminated disease relies on the presence of neutropenia and impaired macrophage function. Fusarial onychomycosis is typically indolent in the immunocompetent host but can lead to dissemination in the setting of systemic immunosuppression. Identification of fusarium on tissue pathology reveals fine, acutely angular, and dichotomously branching septate hyphae, which are not easily distinguished from other hyaline molds. Fusarium species can be isolated on culture media and appear as fluffy/cottony colonies after $2-5$ days of growth [58].

\section{Treatment and Outcomes: Fusarium}

Fusarium species are resistant to most available antifungal agents. Fluconazole, itraconazole, flucytosine, and echinocandins have no activity. Ketoconazole, miconazole, and terbinafine have only limited activity. Voriconazole and posaconazole have moderate activity with respective MICs of $2-8 \mathrm{mg} / \mathrm{L}$ and $0.5-8 \mathrm{mg} / \mathrm{L}$ depending on species. Amphotericin B is the most reliably effective agent, with a MIC of $2 \mathrm{mg} / \mathrm{L}$ across species, but with relatively poor in vivo efficacy $[68,69]$. A combined approach of amphotericin $\mathrm{B}$ and surgical debridement is typically required for clinical cure [70]. The addition of topical nystatin has had success in burn patients [71]. In a case report involving a combined heart-liver transplant recipient that included a review of the literature, Fusarium infections 
in SOTRs were mainly localized, with fungemia described as "uncommon" compared with $20-60 \%$ in HSCT recipients. Additionally, SOTR infection occurred later, mainly $>9$ months post-transplant compared with early post-transplant in HSCT, and was associated with lower mortality, 33\% SOTR vs. 70-100\% HSCT [72].

\section{Endemic Fungi: Histoplasma, Blastomyces, Coccidioides \\ 6.1. Epidemiology}

Histoplasma species and Blastomyces species are endemic to the Ohio and Mississippi River Valleys, and Coccidioides species are endemic to the southwestern states [73-76]. Outside these regions, cases may represent remote travel, reactivation, or donor-derived infection particularly within the first month after transplantation [75,77]. Donor-derived blastomycosis has not been reported [78]. Routine screening and prophylaxis are only recommended for coccidioidomycosis in its endemic region [75].

Endemic mycoses in SOTRs are rare with overall incidence estimated to be $0.2 \%$ [73]. The incidence of histoplasmosis in a TRANSNET study was $0.102 \%$. In a single center in Wisconsin, the incidence of blastomycosis was $0.27 \%$, 18 times higher than in the general population $[73,78]$. Therefore, most guidance on endemic mycoses in liver transplant recipients is extrapolated from cohorts evaluating all SOTRs. Time from transplantation to infection is bimodal; in the TRANSNET study, $40 \%$ of 64 cases were diagnosed within the first 6 months, and 34\% ranging from 2 to 11 years [73]. This pattern was seen in other cohorts $[78,79]$.

\subsection{Pathogenesis and Clinical Manifestations}

Aerosolized conidia and spores, typically inhaled with exposure to disrupted soil, convert from mold to yeast forms at body temperature capable of dissemination [80-82]. Presentation ranges from indolent pulmonary infection to acute respiratory distress syndrome (ARDS) and extrapulmonary dissemination to the skin, osteoarticular system, CNS, and genitourinary system [75]. SOTRs are at increased risk of severe disease, dissemination, and death $[75,76,78,79]$. The rates of dissemination in SOTRs were $81 \%$ for histoplasmosis [79], 75\% for coccidioidomycosis [77], and 37.5\% for blastomycosis in [78]. Blastomycosis disseminates at similar rates regardless of immune status, but SOTRs are more likely to have severe disease, $84.2 \%$ vs. $47.3 \%$ [78].

\subsection{Diagnosis}

The gold standard for diagnosis is isolation on culture, but distinctive histopathology or direct microscopy of affected sites proves infection. Histoplasma antigen or Blastomyces antigen in urine, serum, or body fluid; Coccidioides antibodies in CSF; and two-fold rise in Coccidioides serum antibodies support probable infection [74,83]. In general, the sensitivity of the antigen EIA is higher for urine samples and disseminated disease. For isolated pulmonary histoplasmosis, sensitivity is $65 \%$ for urine, $69 \%$ for serum; and for disseminated disease, $90 \%$ for urine, $80 \%$ for serum [74]. For blastomycosis, sensitivity ranges from $76 \%$ to $90 \%$ and $56 \%$ to $82 \%$ for urine and serum, respectively [74]. The EIA antigen tests are specific for endemic mycosis, but there is significant cross-reactivity between histoplasmosis and blastomycosis [74]. Although serologic studies are less reliable for immunosuppressed SOTRs, the highly sensitive coccidioidomycosis EIAs for IgM and IgG are used for screening, and results are confirmed with a more specific and quantitative complement fixation test [76].

\subsection{Treatment}

Treatment of severe or non-CNS disseminated histoplasmosis or blastomycosis should start with $5 \mathrm{mg} / \mathrm{kg} /$ day of intravenous liposomal amphotericin B for the first 1-2 weeks or until clinical improvement, and with CNS involvement, it should extend to $4-6$ weeks $[75,84]$. This is followed by 12 months of azole therapy, typically itraconazole, $200 \mathrm{mg}$, three times daily for 3 days, then $200 \mathrm{mg}$, twice daily for 12 months [75,84,85]. Fluconazole, $400 \mathrm{mg}$, 
daily for 12 months, is the first line for coccidioidomycosis, but CNS dissemination may require 800-1200 $\mathrm{mg}$ daily, and severe disease requires intravenous amphotericin $B[75,86]$. Therapeutic drug level monitoring of azole treatment is recommended, particularly given interactions with calcineurin inhibitors [75]. Relapsed histoplasmosis is associated with persistent urinary antigen at the end of therapy, $\geq 2.0 \mathrm{ng} / \mathrm{mL}$, and failure to reduce calcineurin inhibitor immunosuppression [79]. If immune suppression is not reversible, then suppressive therapy should be considered [84-86]. For CNS disseminated coccidioidomycosis, suppressive therapy should be lifelong regardless of immune status [86].

\subsection{Outcome}

Mortality inclusive of all endemic mycoses in the TRANSNET study was 16\% [73]. In separate cohorts, mortality was $10 \%$ for histoplasmosis [79], 30-50\% for coccidioidomycosis [76,87], and $21.2 \%$ for blastomycosis [78]. The risk of death from histoplasmosis was associated with increased age, severe disease, fungemia, and higher urine antigen [79]. Blastomycosis mortality was highest, $66.7 \%$; in cases with ARDS after diagnosis was delayed by two or more courses of antibiotics [78].

\section{Prophylaxis of Fungal Infection}

As we have shown, liver transplant recipients experience invasive fungal disease from a wide range of etiologies, but with infections due to Candida species being predominant, and Aspergillosis being the second most common etiology.

With these patterns, antifungal prophylaxis has been an attractive option, although the ideal approach remains unclear. This is further complicated by evolving eras, with the availability of new antifungals, changes in patient characteristics and management strategies over time, and more prevalent non-albicans, Candida infections. Prophylaxis strategies toward Candida and Aspergillus have been tested, and recommendations exist for both.

Regarding Candida prevention, studies have demonstrated the safety and efficacy of universal prophylaxis with reduction in IFI, although without mortality benefit [88-91]. Lack of mortality benefit, as well as a high number needed for treatment, has driven interest in targeted prophylaxis. This approach has shown efficacy, reducing IFI, and safety in numerous studies with a variety of agents, including fluconazole, amphotericin B, voriconazole, and echinocandins [92-100].

The ID AST COP Candida guidelines [22] define high risk as any one of the following: retransplantation, reoperation, renal failure requiring dialysis, transfusion $\geq 40$ units of cellular blood products including autotransfusion, choledochojejunostomy, and Candida colonization perioperatively. They also list considerations for MELD $\geq 30$, biliary leaks, and living liver transplant.

Just as the indications and agents studied vary, so does duration. Studies range from 5 days to 10 weeks. We recommend continuation through 2-4 weeks or until discharge if sooner. As noted, the ideal agent is unclear, but given its availability, tolerability, and excellent efficacy in clinical trials, we would recommend fluconazole as the first-line agent. Consideration of echinocandins is appropriate if the risk for fluconazole-resistant Candida colonization is felt to be very high due to preceding azole exposure or known resistant Candida colonization.

Overall, targeted Candida prophylaxis in high-risk recipients is safe and efficacious in decreasing post-transplant IC, and protocols to ensure its appropriate utilization can improve outcomes [101].

A more difficult decision concerns Aspergillus prophylaxis in liver transplant recipients. Although the second most common IFI post-liver transplant, it remains relatively rare with rates varying from $1 \%$ to $9 \%$, although rates as low as $<1 \%$ have also been reported [102]. The infrequent but potentially devastating nature suggests that targeted prophylaxis may be ideal, but to date, data are suboptimal. 
Currently, the IDSA does not make specific recommendations on Aspergillus prophylaxis in liver transplant recipients, and recommending institution-specific guidelines based on local epidemiology and noting optimal duration of prophylaxis are unknown [32]. However, the ID AST COP released guidelines in 2019 recommending targeted prophylaxis in cases of retransplant, renal replacement therapy at the time of or within 7 days of transplant, and reoperation involving the thoracic or intra-abdominal cavity. They recommend echinocandin or voriconazole for targeted prophylaxis, with lipid formulation amphotericin B as alternative, with a duration of 14-21 days [102].

Neyra et al. performed a retrospective study evaluating the performance of risk factors for invasive mold in 534 liver transplant recipients from 2010 to 2014. Cases were rare, with $0.78 \%$ of those with risk factors infected vs. $0.98 \%$ of those without risk factors infected. Of the $18 \%$ of cases with risk factors receiving mold prophylaxis, none suffered mold infection. This study highlights the low sensitivity of traditional mold risk factors, and overall infrequent occurrence hints at the potential benefit of mold prophylaxis and emphasizes that better methods for targeting prophylaxis are needed [103].

Robust data on the optimal agent or duration of prophylaxis are lacking. A trial on universal voriconazole prophylaxis vs. targeted prophylaxis demonstrated good tolerance and no difference in IFI rates, suggesting that targeted prophylaxis allows for the safe reduction of antifungal exposure [93]. Evaluation of echinocandins vs. fluconazole prophylaxis has failed to demonstrate clear superiority, although one trial did show lower rates of Aspergillus identification post-liver transplant, $3 \%$ vs. 9\% when utilizing anidulafungin vs. fluconazole $[104,105]$. A retrospective evaluation of caspofungin vs. no prophylaxis across eras at a single center found a decrease in IPA diagnoses at 90 days post-transplant, $0.5 \%$ vs. 3.3\%, suggesting possible efficacy [106]. Balogh et al. retrospectively evaluated highrisk patients treated with voriconazole prophylaxis and found no breakthrough invasive Aspergillus episodes and relatively good tolerance [107].

Recently, a retrospective evaluation of Aspergillus-colonized liver transplant recipients, all of whom received Aspergillus-directed antifungal prophylaxis, predominantly with voriconazole, found only one death due to fungal infection, but also noted decreased survival from baseline, and breakthrough infections were identified. The median duration of prophylaxis was also prolonged, 85 days vs. typical 8 weeks [108]. This suggests that transplantation can be sought with Aspergillus colonization but carries increased risk, and that any pretransplant colonization demands prophylaxis and expert management.

Overall, targeted Aspergillus prophylaxis remains controversial due to lack of highquality prospective trials, suboptimal performance of risk factors, and likely regional and temporal variation of baseline risk. Mold prophylaxis appears to be at least safe and may be appropriate based on ID AST COP recommendations, but further prospective trials are necessary. Currently, institution-specific approaches based on local trends seem most appropriate.

\section{Conclusions}

Progress in the identification, prophylaxis, and treatment of IFI after liver transplantation has resulted in encouraging trends in the incidence, morbidity, and mortality from these dreaded infections. Continued research to help identify patients most at risk and the most effective prevention is needed.

Author Contributions: Conceptualization, J.S.; writing-original draft preparation, J.S., C.S., M.J., and M.S.; writing-review and editing J.S., C.S., M.J., and M.S. All authors have read and agreed to the published version of the manuscript.

Funding: This research received no external funding.

Institutional Review Board Statement: Not applicable.

Informed Consent Statement: Not applicable.

Conflicts of Interest: The authors declare no conflict of interest. 


\section{References}

1. Biancofiore, G.; Bindi, M.L.; Baldassarri, R.; Romanelli, A.M.; Catalano, G.; Filipponi, F.; Vagelli, A.; Mosca, F. Antifungal prophylaxis in liver transplant recipients: A randomized placebo-controlled study. Transpl. Int. 2002, 15, 341-347. [CrossRef] [PubMed]

2. Singh, N.; Avery, R.K.; Munoz, P.; Pruett, T.L.; Alexander, B.; Jacobs, R.; Tollemar, J.G.; Dominguez, E.A.; Yu, C.M.; Paterson, D.L.; et al. Trends in Risk Profiles for and Mortality Associated with Invasive Aspergillosis among Liver Transplant Recipients. Clin. Infect. Dis. 2003, 36, 46-52. [CrossRef] [PubMed]

3. Lahmer, T.; Messer, M.; Schwerdtfeger, C.; Rasch, S.; Lee, M.; Saugel, B.; Schmid, R.M.; Huber, W. Invasive Mycosis in Medical Intensive Care Unit Patients with Severe Alcoholic Hepatitis. Mycopathologia 2014, 177, 193-197. [CrossRef]

4. Singh, N.; Husain, S.; de Vera, M.; Gayowski, T.; Cacciarelli, T.V. Cryptococcus neoformans Infection in Patients with Cirrhosis, Including Liver Transplant Candidates. Medicine 2004, 83, 188-192. [CrossRef] [PubMed]

5. Singh, N.; Wagener, M.M.; Marino, I.R.; Gayowski, T. Trends in invasive fungal infections in liver transplant recipients: Correlation with evolution in transplantation practices. Transplantation 2002, 73, 63-67. [CrossRef] [PubMed]

6. Hosseini-Moghaddam, S.M.; Ouédraogo, A.; Naylor, K.L.; Bota, S.E.; Husain, S.; Nash, D.M.; Paterson, J.M. Incidence and outcomes of invasive fungal infection among solid organ transplant recipients: A population-based cohort study. Transpl. Infect. Dis. 2020, 22, e13250. [CrossRef]

7. Pappas, P.G.; Alexander, B.D.; Andes, D.R.; Hadley, S.; Kauffman, C.A.; Freifeld, A.; Anaissie, E.J.; Brumble, L.M.; Herwaldt, L.; Ito, J.; et al. Invasive Fungal Infections among Organ Transplant Recipients: Results of the Transplant-Associated Infection Surveillance Network (transnet). Clin. Infect. Dis. 2010, 50, 1101-1111. [CrossRef]

8. $\quad$ van Delden, C.; Stampf, S.; Hirsch, H.H.; Manuel, O.; Meylan, P.; Cusini, A.; Hirzel, C.; Khanna, N.; Weisser, M.; Garzoni, C.; et al. Burden and Timeline of Infectious Diseases in the First Year After Solid Organ Transplantation in the Swiss Transplant Cohort Study. Clin. Infect. Dis. 2020, 71, e159-e169. [CrossRef] [PubMed]

9. Fernández-Ruiz, M.; Cardozo, C.; Salavert, M.; Aguilar-Guisado, M.; Escolà-Vergé, L.; Muñoz, P.; Gioia, F.; Montejo, M.; Merino, P.; Cuervo, G.; et al. Candidemia in solid organ transplant recipients in Spain: Epidemiological trends and determinants of outcome. Transpl. Infect. Dis. 2019, 21, e13195. [CrossRef]

10. Andes, D.R.; Safdar, N.; Baddley, J.W.; Alexander, B.; Brumble, L.; Freifeld, A.; Hadley, S.; Herwaldt, L.; Kauffman, C.; Lyon, G.M.; et al. The epidemiology and outcomes of invasive Candida infections among organ transplant recipients in the United States: Results of the Transplant-Associated Infection Surveillance Network (transnet). Transpl. Infect. Dis. 2016, 18, 921-931. [CrossRef]

11. Theodoropoulos, N.M.; Bolstorff, B.; Bozorgzadeh, A.; Brandeburg, C.; Cumming, M.; Daly, J.S.; Ellison, R.T.; Forsberg, K.; Gade, L.; Gibson, L.; et al. Candida auris outbreak involving liver transplant recipients in a surgical intensive care unit. Arab. Archaeol. Epigr. 2020, 20, 3673-3679. [CrossRef]

12. Kullberg, B.J.; Arendrup, M.C. Invasive Candidiasis. N. Engl. J. Med. 2015, 373, 1445-1456. [CrossRef]

13. Collins, L.A.; Samore, M.H.; Roberts, M.S.; Luzzati, R.; Jenkins, R.L.; Lewis, W.D.; Karchmer, A.W. Risk factors for invasive fungal infections complicating orthotopic liver transplantation. J. Infect. Dis. 1994, 170, 644-652. [CrossRef] [PubMed]

14. Hadley, S.; Samore, M.H.; Lewis, W.D.; Jenkins, R.L.; Karchmer, A.W.; Hammer, S.M. Major infectious complications after orthotopic liver transplantation and comparison of outcomes in patients receiving cyclosporine or FK506 as primary immunosuppression. Transplantation 1995, 59, 851-859. [CrossRef] [PubMed]

15. Viehman, J.A.; Clancy, C.J.; Clarke, L.; Shields, R.K.; Silveira, F.P.; Kwak, E.J.; Pascalis, V.; Christopher, H.; Abhinav, H.; Hong, N.M.; et al. Surgical Site Infections after Liver Transplantation: Emergence of Multidrug-Resistant Bacteria and Implications for Prophylaxis and Treatment Strategies. Transplantation 2016, 100, 2107-2114. [CrossRef]

16. Marik, P.E. Fungal infections in solid organ transplantation. Expert Opin. Pharmacother. 2006, 7, 297-305. [CrossRef]

17. Clancy, C.J.; Nguyen, M.H. Diagnosing Invasive Candidiasis. J. Clin. Microbiol. 2018, 56. [CrossRef] [PubMed]

18. Sulahian, A.; Porcher, R.; Bergeron, A.; Touratier, S.; Raffoux, E.; Menotti, J.; DeRouin, F.; Ribaud, P. Use and Limits of (1-3)-DGlucan Assay (Fungitell), Compared to Galactomannan Determination (Platelia aspergillus), for Diagnosis of Invasive Aspergillosis. J. Clin. Microbiol. 2014, 52, 2328-2333. [CrossRef]

19. Levesque, E.; El Anbassi, S.; Sitterle, E.; Foulet, F.; Merle, J.C.; Botterel, F. Contribution of (1,3)-Beta-d-Glucan to Diagnosis of Invasive Candidiasis after Liver Transplantation. J. Clin. Microbiol. 2014, 53, 771-776. [CrossRef]

20. Sexton, D.J.; Bentz, M.L.; Welsh, R.M.; Litvintseva, A.P. Evaluation of a new T2 Magnetic Resonance assay for rapid detection of emergent fungal pathogen Candida auris on clinical skin swab samples. Mycoses 2018, 61, 786-790. [CrossRef]

21. Avni, T.; Leibovici, L.; Paul, M. PCR Diagnosis of Invasive Candidiasis: Systematic Review and Meta-Analysis. J. Clin. Microbiol. 2011, 49, 665-670. [CrossRef]

22. Aslam, S.; Rotstein, C. Candida infections in solid organ transplantation: Guidelines from the American Society of Transplantation Infectious Diseases Community of Practice. Clin. Transplant. 2019, 33, e13623. [CrossRef]

23. Pappas, P.G.; Kauffman, C.A.; Andes, D.R.; Clancy, C.J.; Marr, K.A.; Ostrosky-Zeichner, L.; Reboli, A.C.; Schuster, M.G.; Vazquez, J.A.; Walsh, Y.G.; et al. Clinical Practice Guideline for the Management of Candidiasis: 2016 Update by the Infectious Diseases Society of America. Clin. Infect. Dis. 2015, 62, e1-e50. [CrossRef] [PubMed] 
24. Barchiesi, F.; Mazzocato, S.; Mazzanti, S.; Gesuita, R.; Skrami, E.; Fiorentini, A.; Singh, N. Invasive aspergillosis in liver transplant recipients: Epidemiology, clinical characteristics, treatment, and outcomes in 116 cases. Liver Transplant. 2015, 21, $204-212$. [CrossRef] [PubMed]

25. Steinbach, W.J.; Marr, K.A.; Anaissie, E.J.; Azie, N.; Quan, S.-P.; Meier-Kriesche, H.-U.; Apewokin, S.; Horn, D.L. Clinical epidemiology of 960 patients with invasive aspergillosis from the PATH Alliance registry. J. Infect. 2012, 65, 453-464. [CrossRef] [PubMed]

26. Briegel, J.; Forst, H.; Spill, B.; Haas, A.; Grabein, B.; Haller, M.; Kilger, E.; Jauch, K.W.; Maag, K.; Ruckdeschel, G.; et al. Risk factors for systemic fungal infections in liver transplant recipients. Eur. J. Clin. Microbiol. Infect. Dis. 1995, 14, 375-382. [CrossRef] [PubMed]

27. Kusne, S.; Torre-Cisneros, J.; Mañez, R.; Irish, W.; Martin, M.; Fung, J.; Simmons, R.L.; Starzl, T.E. Factors Associated with Invasive Lung Aspergillosis and the Significance of Positive Aspergillus Culture after Liver Transplantation. J. Infect. Dis. 1992, 166, 1379-1383. [CrossRef]

28. Aït-Ammar, N.; Levesque, E.; Murat, J.-B.; Imbert, S.; Foulet, F.; Dannaoui, E.; Botterel, F. Aspergillus pseudodeflectus: A new human pathogen in liver transplant patients. BMC Infect. Dis. 2018, 18, 648. [CrossRef]

29. Choudhury, N.; Khan, A.B.; Tzvetanov, I.; Garcia-Roca, R.; Oberholzer, J.; Benedetti, E.; Jeon, H. Multiple Aspergillus Brain Abscesses After Liver Transplantation. Transplant 2014, 97, e72-e73. [CrossRef]

30. Tsitsopoulos, P.P.; Tsoulfas, G.; Tsonidis, C.; Imvrios, G.; Papanikolaou, V.; Giakoustidis, D.; Marinopoulos, D.; Takoudas, D.; Tsitsopoulos, P.D. Successful, combined long-term treatment of cerebral aspergillosis in a liver transplant patient. Virulence 2010, 1, 465-467. [CrossRef]

31. Tsiodras, S.; Zafiropoulou, R.; Giotakis, J.; Imbrios, G.; Antoniades, A.; Manesis, E.K. Deep sinus aspergillosis in a liver transplant recipient successfully treated with a combination of caspofungin and voriconazole. Transpl. Infect. Dis. 2004, 6, 37-40. [CrossRef] [PubMed]

32. Patterson, T.F.; Thompson, G.R., III; Denning, D.W.; Fishman, J.A.; Hadley, S.; Herbrecht, R.; Kontoyiannis, D.P.; Marr, K.A.; Morrison, V.A.; Nguyen, M.H.; et al. Practice Guidelines for the Diagnosis and Management of Aspergillosis: 2016 Update by the Infectious Diseases Society of America. Clin. Infect. Dis. 2016, 63, e1-e60. [CrossRef] [PubMed]

33. Qin, J.; Fang, Y.; Dong, Y.; Zhu, K.; Wu, B.; An, Y.; Shan, H. Radiological and clinical findings of 25 patients with invasive pulmonary aspergillosis: Retrospective analysis of 2150 liver transplantation cases. Br. J. Radiol. 2012, 85, e429-e435. [CrossRef] [PubMed]

34. Johnson, P.J.; Lydiatt, W.M.; Huerter, J.V.; Ogren, F.P.; Vose, J.M.; Stratta, R.J.; Yonkers, A.J. Invasive Fungal Sinusitis following Liver or Bone Marrow Transplantation. Am. J. Rhinol. 1994, 8, 77-84. [CrossRef]

35. Singh, N.; Winston, D.J.; Limaye, A.P.; Pelletier, S.; Safdar, N.; Morris, M.I.; Meneses, K.; Busuttil, R.W.; Wagener, M.M.; Wheat, L.J. Performance Characteristics of Galactomannan and $\beta$-d-Glucan in High-Risk Liver Transplant Recipients. Transplantation 2015, 99, 2543-2550. [CrossRef]

36. Clancy, C.J.; Jaber, R.A.; Leather, H.L.; Wingard, J.R.; Staley, B.; Wheat, L.J.; Cline, C.L.; Rand, K.H.; Schain, D.; Baz, M.; et al. Bronchoalveolar Lavage Galactomannan in Diagnosis of Invasive Pulmonary Aspergillosis among Solid-Organ Transplant Recipients. J. Clin. Microbiol. 2007, 45, 1759-1765. [CrossRef]

37. Levesque, E.; Rizk, F.; Noorah, Z.; Aït-Ammar, N.; Cordonnier-Jourdin, C.; El Anbassi, S.; Bonnal, C.; Azoulay, D.; Merle, J.-C.; Botterel, F. Detection of (1,3)- $\beta$-d-Glucan for the Diagnosis of Invasive Fungal Infection in Liver Transplant Recipients. Int. J. Mol. Sci. 2017, 18, 862. [CrossRef]

38. Maziarz, E.K.; Perfect, J.R. Cryptococcosis. Infect. Dis. Clin. N. Am. 2016, 30, 179-206. [CrossRef]

39. Fang, W.; Fa, Z.; Liao, W. Epidemiology of Cryptococcus and cryptococcosis in China. Fungal Genet. Biol. 2015, 78, 7-15. [CrossRef]

40. Forrest, G.N.; Bhalla, P.; DeBess, E.E.; Winthrop, K.L.; Lockhart, S.R.; Mohammadi, J.; Cieslak, P.R. Cryptococcus gattii infection in solid organ transplant recipients: Description of Oregon outbreak cases. Transpl. Infect. Dis. 2015, 17, 467-476. [CrossRef]

41. Baddley, J.W.; Forrest, G.N.; The AST Infectious Diseases Community of Practice. Cryptococcosis in solid organ transplantationGuidelines from the American Society of Transplantation Infectious Diseases Community of Practice. Clin. Transplant. 2019, 33, e13543. [CrossRef] [PubMed]

42. Singh, N.; Dromer, F.; Perfect, J.R.; Lortholary, O. Immunocompromised Hosts: Cryptococcosis in Solid Organ Transplant Recipients: Current State of the Science. Clin. Infect. Dis. 2008, 47, 1321-1327. [CrossRef]

43. Wu, G.; Vilchez, R.; Eidelman, B.; Fung, J.; Kormos, R.; Kusne, S. Cryptococcal meningitis: An analysis among 5521 consecutive organ transplant recipients. Transpl. Infect. Dis. 2002, 4, 183-188. [CrossRef] [PubMed]

44. Casadevall, A. Cryptococci at the brain gate: Break and enter or use a Trojan horse? J. Clin. Investig. 2010, 120, 1389-1392. [CrossRef] [PubMed]

45. Perfect, J.R.; Bicanic, T. Cryptococcosis diagnosis and treatment: What do we know now. Fungal Genet. Biol. 2015, 78, 49-54. [CrossRef] [PubMed]

46. Singh, N.; Alexander, B.D.; Lortholary, O.; Dromer, F.; Gupta, K.L.; John, G.T.; del Busto, R.; Klintmalm, G.B.; Somani, J.; Lyon, G.M.; et al. Cryptococcus neoformans in organ transplant recipients: Impact of calcineurin-inhibitor agents on mortality. J. Infect. Dis. 2007, 195, 756-764. [CrossRef] [PubMed]

47. Bauzá, A.; Redondo, P.; Rubio, M. Primary cutaneous cryptococcal cellulitis secondary to insect bite in an immunosupressed patient after liver transplantation. Clin. Exp. Dermatol. 2005, 30, 241-243. [CrossRef] 
48. Nosanchuk, J.D.; Shoham, S.; Fries, B.C.; Shapiro, D.S.; Levitz, S.M.; Casadevall, A. Evidence of zoonotic transmission of Cryptococcus neoformans from a pet cockatoo to an immunocompromised patient. Ann. Intern. Med. 2000, 132, 205-208. [CrossRef] [PubMed]

49. Ferreira, G.D.S.A.; Watanabe, A.L.C.; de Carvalho Trevizoli, N.; Jorge, F.M.F.; de Fatima Couto, C.; de Campos, P.B.; Caja, G.O.N. Transmission of cryptococcosis by liver transplantation: A case report and review of literature. World J. Hepatol. 2020, 12, 253-261. [CrossRef]

50. Vijayan, T.; Chiller, T.; Klausner, J.D. Sensitivity and specificity of a new cryptococcal antigen lateral flow assay in serum and cerebrospinal fluid. MLO Med. Lab. Obs. 2013, 45, 16. [PubMed]

51. Perfect, J.R.; Dismukes, W.E.; Dromer, F.; Goldman, D.L.; Graybill, J.R.; Hamill, R.J.; Harrison, T.S.; Larsen, R.A.; Lortholary, O.; Nguyen, M.-L.; et al. Clinical practice guidelines for the management of cryptococcal disease: 2010 update by the infectious diseases society of america. Clin. Infect. Dis. 2010, 50, 291-322. [CrossRef] [PubMed]

52. Singh, N.; Lortholary, O.; Alexander, B.D.; Gupta, K.L.; John, G.T.; Pursell, K.; Munoz, P.; Klintmalm, G.B.; Stosor, V.; Del Busto, R.; et al. An Immune Reconstitution Syndrome-Like Illness Associated withCryptococcus neoformans Infection in Organ Transplant Recipients. Clin. Infect. Dis. 2005, 40, 1756-1761. [CrossRef] [PubMed]

53. Scemla, A.; Gerber, S.; Duquesne, A.; Parize, P.; Martinez, F.; Anglicheau, D.; Snanoudj, R.; Zuber, M.; Bougnoux, M.-E.; Legendre, C.; et al. Dramatic Improvement of Severe Cryptococcosis-Induced Immune Reconstitution Syndrome With Adalimumab in a Renal Transplant Recipient. Arab. Archaeol. Epigr. 2015, 15, 560-564. [CrossRef] [PubMed]

54. Wingard, J.R. Fungal infections after bone marrow transplant. Biol. Blood Marrow Transplant. 1999, 5, 55-68. [CrossRef] [PubMed]

55. Husain, S.; Muñoz, P.; Forrest, G.; Alexander, B.D.; Somani, J.; Brennan, K.; Wagener, M.M.; Singh, N. Infections Due to Scedosporium apiospermum and Scedosporium prolificans in Transplant Recipients: Clinical Characteristics and Impact of Antifungal Agent Therapy on Outcome. Clin. Infect. Dis. 2005, 40, 89-99. [CrossRef] [PubMed]

56. Jiménez, C.; Lumbreras, C.; Aguado, J.M.; Loinaz, C.; Paseiro, G.; Andrés, A.; Morales, J.M.; Sánchez, G.; García, I.; Del Palacio, A.; et al. Successful Treatment of Mucor Infection after Liver or Pancreas-Kidney Transplantation. Transplantation 2002, 73, 476-480. [CrossRef] [PubMed]

57. Wajszczuk, C.P.; Dummer, J.S.; Ho, M.; Van Thiel, D.H.; Starzl, T.E.; Iwatsuki, S.; Shaw, B. Fungal infections in liver transplant recipients. Transplantation 1985, 40,347-353. [CrossRef]

58. Yamasmith, E.; Chongtrakool, P.; Chayakulkeeree, M. Isolated pulmonary fusariosis caused by Neocosmospora pseudensiformis in a liver transplant recipient: A case report and review of the literature. Transpl. Infect. Dis. 2020, 22, e13344. [CrossRef]

59. Cortez, K.J.; Roilides, E.; Quiroz-Telles, F.; Meletiadis, J.; Antachopoulos, C.; Knudsen, T.; Buchanan, W.; Milanovich, J.; Sutton, D.A.; Fothergill, A.; et al. Infections Caused by Scedosporium spp. Clin. Microbiol. Rev. 2008, 21, 157-197. [CrossRef]

60. Kowacs, P.A.; Silvado, C.E.S.; De Almeida, S.M.; Ramos, M.; Abrão, K.; E Madaloso, L.; Pinheiro, R.L.; Werneck, L.C. Infection of the CNS by Scedosporium apiospermum after near drowning. Report of a fatal case and analysis of its confounding factors. $J$. Clin. Pathol. 2004, 57, 205-207. [CrossRef]

61. Leek, R.; Aldag, E.; Nadeem, I.; Gunabushanam, V.; Sahajpal, A.; Kramer, D.J.; Walsh, T.J. Scedosporiosis in a Combined Kidney and Liver Transplant Recipient: A Case Report of Possible Transmission from a Near-Drowning Donor. Case Rep. Transplant. 2016, 2016, 1-7. [CrossRef] [PubMed]

62. Sahi, H.; Avery, R.K.; Minai, O.A.; Hall, G.; Mehta, A.C.; Raina, P.; Budev, M. Scedosporium apiospermum (Pseudoallescheria boydii) Infection in Lung Transplant Recipients. J. Hear. Lung Transplant. 2007, 26, 350-356. [CrossRef]

63. Goldman, C.; Akiyama, M.J.; Torres, J.; Louie, E.; Meehan, S. Scedosporium apiospermum infections and the role of combination antifungal therapy and GM-CSF: A case report and review of the literature. Med Mycol. Case Rep. 2016, 11, 40-43. [CrossRef]

64. Ribes, J.A.; Vanover-Sams, C.L.; Baker, D.J. Zygomycetes in human disease. Clin. Microbiol. Rev. 2000, 13, 236-301. [CrossRef]

65. Almyroudis, N.G.; Sutton, D.A.; Linden, P.; Rinaldi, M.G.; Fung, J.; Kusne, S. Zygomycosis in Solid Organ Transplant Recipients in a Tertiary Transplant Center and Review of the Literature. Arab. Archaeol. Epigr. 2006, 6, 2365-2374. [CrossRef]

66. Singh, N.; Gayowski, T.; Singh, J.; Yu, V.L. Invasive Gastrointestinal Zygomycosis in a Liver Transplant Recipient: Case Report and Review of Zygomycosis in Solid-Organ Transplant Recipients. Clin. Infect. Dis. 1995, 20, 617-620. [CrossRef] [PubMed]

67. Tedder, M.; Spratt, J.A.; Anstadt, M.P.; Hegde, S.S.; Tedder, S.D.; Lowe, J.E. Pulmonary mucormycosis: Results of medical and surgical therapy. Ann. Thorac. Surg. 1994, 57, 1044-1050. [CrossRef]

68. Al-Hatmi, A.M.S.; Meis, J.F.; De Hoog, G.S. Fusarium: Molecular Diversity and Intrinsic Drug Resistance. PLoS Pathog. 2016, 12, e1005464. [CrossRef]

69. Pujol, I.; Guarro, J.; Gene, J.; Sala, J. In-vitro antifungal susceptibility of clinical and environmental Fusarium spp. strains. J. Antimicrob. Chemother. 1997, 39, 163-167. [CrossRef]

70. Heinz, T.; Perfect, J.; Schell, W.; Ritter, E.; Ruff, G.; Serafin, D. Soft-Tissue Fungal Infections: Surgical Management of 12 Immunocompromised Patients. Plast. Reconstr. Surg. 1996, 97, 1391-1399. [CrossRef] [PubMed]

71. Barret, J.; Ramzy, P.; Heggers, J.; Villareal, C.; Herndon, D.; Desai, M. Topical nystatin powder in severe burns: A new treatment for angioinvasive fungal infections refractory to other topical and systemic agents. Burns 1999, 25, 505-508. [CrossRef]

72. Sampathkumar, P.; Paya, C.V. Fusarium infection after solid-organ transplantation. Clin. Infect. Dis. 2001, 32, 1237-1240. [CrossRef] 
73. Kauffman, C.; Freifeld, A.; Andes, D.; Baddley, J.; Herwaldt, L.; Walker, R.; Alexander, B.; Anaissie, E.; Benedict, K.; Ito, J.; et al. Endemic fungal infections in solid organ and hematopoietic cell transplant recipients enrolled in the Transplant-Associated Infection Surveillance Network (transnet). Transpl. Infect. Dis. 2014, 16, 213-224. [CrossRef] [PubMed]

74. Linder, K.A.; Kauffman, C.A. Current and New Perspectives in the Diagnosis of Blastomycosis and Histoplasmosis. J. Fungi 2020, 7, 12. [CrossRef] [PubMed]

75. Miller, R.; Assi, M.; The AST Infectious Diseases Community of Practice. Endemic fungal infections in solid organ transplant recipients-Guidelines from the American Society of Transplantation Infectious Diseases Community of Practice. Clin. Transplant. 2019, 33, e13553. [CrossRef] [PubMed]

76. Nanayakkara, D.D.; Blodget, E. Coccidioidomycosis in solid organ transplant recipients. Curr. Opin. Organ Transplant. 2019, 24, 465-468. [CrossRef] [PubMed]

77. Blair, J.E. Coccidioidomycosis in liver transplantation. Liver Transplant. 2006, 12, 31-39. [CrossRef]

78. McBride, J.A.; Sterkel, A.K.; Matkovic, E.; Broman, A.T.; Gibbons-Burgener, S.N.; Gauthier, G.M. Clinical Manifestations and Outcomes in Immunocompetent and Immunocompromised Patients with Blastomycosis. Clin. Infect. Dis. 2020, 72, 1594-1602. [CrossRef]

79. Assi, M.; Martin, S.; Wheat, L.J.; Hage, C.; Freifeld, A.; Avery, R.; Baddley, J.W.; Vergidis, P.; Miller, R.; Andes, D.; et al. Histoplasmosis after solid organ transplant. Clin. Infect. Dis. 2013, 57, 1542-1549. [CrossRef]

80. Kauffman, C.A.; Miceli, M.H. Histoplasmosis and Blastomycosis in Solid Organ Transplant Recipients. J. Fungi 2015, 1, 94-106. [CrossRef]

81. Nguyen, C.; Barker, B.; Hoover, S.; Nix, D.E.; Ampel, N.M.; Frelinger, J.A.; Orbach, M.J.; Galgiani, J.N. Recent Advances in Our Understanding of the Environmental, Epidemiological, Immunological, and Clinical Dimensions of Coccidioidomycosis. Clin. Microbiol. Rev. 2013, 26, 505-525. [CrossRef]

82. Saccente, M.; Woods, G.L. Clinical and Laboratory Update on Blastomycosis. Clin. Microbiol. Rev. 2010, 23, 367-381. [CrossRef]

83. Donnelly, J.P.; Chen, S.C.; Kauffman, C.A.; Steinbach, W.J.; Baddley, J.W.; Verweij, P.E.; Clancy, C.J.; Wingard, J.R.; Lockhart, S.R.; Groll, A.H.; et al. Revision and Update of the Consensus Definitions of Invasive Fungal Disease From the European Organization for Research and Treatment of Cancer and the Mycoses Study Group Education and Research Consortium. Clin. Infect. Dis. 2019, 71, 1367-1376. [CrossRef] [PubMed]

84. Wheat, L.J.; Freifeld, A.G.; Kleiman, M.B.; Baddley, J.W.; McKinsey, D.S.; Loyd, J.; Kauffman, C.A. Clinical Practice Guidelines for the Management of Patients with Histoplasmosis: 2007 Update by the Infectious Diseases Society of America. Clin. Infect. Dis. 2007, 45, 807-825. [CrossRef] [PubMed]

85. Chapman, S.W.; Dismukes, W.E.; Proia, L.A.; Bradsher, R.W.; Pappas, P.G.; Threlkeld, M.G.; Kauffman, C.A. Clinical Practice Guidelines for the Management of Blastomycosis: 2008 Update by the Infectious Diseases Society of America. Clin. Infect. Dis. 2008, 46, 1801-1812. [CrossRef]

86. Galgiani, J.N.; Ampel, N.M.; Blair, J.E.; Catanzaro, A.; Geertsma, F.; Hoover, S.E.; Johnson, R.H.; Kusne, S.; Lisse, J.; MacDonald, J.D.; et al. 2016 Infectious Diseases Society of America (IDSA) Clinical Practice Guideline for the Treatment of Coccidioidomycosis. Clin. Infect. Dis. 2016, 63, e112-e146. [CrossRef]

87. Holt, C.D.; Winston, D.J.; Kubak, B.; Imagawa, D.K.; Martin, P.; Goldstein, L.; Olthoff, K.; Millis, J.M.; Shaked, A.; Shackleton, C.R.; et al. Coccidioidomycosis in liver transplant patients. Clin. Infect. Dis. 1997, 24, 216-221. [CrossRef]

88. Lumbreras, C.; Cuervas-Mons, V.; Jara, P.; Del Palacio, A.; Turrion, V.S.; Barrios, C.; Moreno, E.; Noriega, A.R.; Paya, C.V. Randomized Trial of Fluconazole versus Nystatin for the Prophylaxis of Candida Infection following Liver Transplantation. J. Infect. Dis. 1996, 174, 583-588. [CrossRef] [PubMed]

89. Sharpe, M.D.; Ghent, C.; Grant, D.; Horbay, G.L.A.; McDougal, J.; Colby, W.D. Efficacy and safety of itraconazole prophylaxis for fungal infections after orthotopic liver transplantation: A prospective, randomized, double-blind study. Transplantation 2003, 76, 977-983. [CrossRef] [PubMed]

90. Winston, D.J.; Busuttil, R.W. Randomized controlled trial of oral itraconazole solution versus intravenous/oral fluconazole for prevention of fungal infections in liver transplant recipients1. Transplantation 2002, 74, 688-695. [CrossRef]

91. Winston, D.J.; Pakrasi, A.; Busuttil, R.W. Prophylactic Fluconazole in Liver Transplant Recipients. Ann. Intern. Med. 1999, 131, 729-737. [CrossRef]

92. Castroagudín, J.; Ponton, C.; Bustamante, M.; Otero, E.; Martínez, J.; Tomé, S.; Conde, R.; Segade, F.; Delgado, M.; Brage, A.; et al. Prospective Interventional Study to Evaluate the Efficacy and Safety of Liposomal Amphotericin B as Prophylaxis of Fungal Infections in High-Risk Liver Transplant Recipients. Transplant. Proc. 2005, 37, 3965-3967. [CrossRef]

93. Eschenauer, G.A.; Kwak, E.J.; Humar, A.; Potoski, B.A.; Clarke, L.G.; Shields, R.K.; Abdel-Massih, R.; Silveira, F.P.; Vergidis, P.; Clancy, C.J.; et al. Targeted Versus Universal Antifungal Prophylaxis Among Liver Transplant Recipients. Arab. Archaeol. Epigr. 2015, 15, 180-189. [CrossRef]

94. Fortún, J.; Martín-Dávila, P.; Montejo, M.; Muñoz, P.; Cisneros, J.M.; Ramos, A.; Aragón, C.; Blanes, M.; Juan, R.S.; Gavaldà, J.; et al. Prophylaxis With Caspofungin for Invasive Fungal Infections in High-Risk Liver Transplant Recipients. Transplantation 2009, 87, 424-435. [CrossRef]

95. Lavezzo, B.; Stratta, C.; Ballaris, M.; Tandoi, F.; Panio, A.; Donadio, P.; Salizzoni, M. Invasive Candida Infections in Low Risk Liver Transplant Patients Given No Antifungal Prophylaxis in the Post-operative Period. Transplant. Proc. 2014, 46, $2312-2313$. [CrossRef] 
96. Lorf, T.; Braun, F.; Rüchel, R.; Müller, A.; Sattler, B.; Ringe, B. Systemic mycoses during prophylactical use of liposomal amphotericin B (Ambisome ${ }^{\circledR}$ ) after liver transplantation. Mycoses 1999, 42, 47-53. [CrossRef] [PubMed]

97. Pappas, P.G.; Andes, D.; Schuster, M.; Hadley, S.; Rabkin, J.; Merion, R.M.; Kauffman, C.A.; Huckabee, C.; Cloud, G.A.; Dismukes, W.E.; et al. Invasive Fungal Infections in Low-Risk Liver Transplant Recipients: A Multi-Center Prospective Observational Study. Arab. Archaeol. Epigr. 2006, 6, 386-391. [CrossRef] [PubMed]

98. Saliba, F.; Delvart, V.; Ichaï, P.; Kassis, N.; Botterel, F.; Mihaila, L.; Azoulay, D.; Adam, R.; Castaing, D.; Bretagne, S.; et al. Outcomes associated with amphotericin B lipid complex (ABLC) prophylaxis in high-risk liver transplant patients. Med. Mycol. 2013, 51, 155-163. [CrossRef] [PubMed]

99. Sun, H.-Y.; Cacciarelli, T.V.; Singh, N. Micafungin Versus Amphotericin B Lipid Complex for the Prevention of Invasive Fungal Infections in High-Risk Liver Transplant Recipients. Transplantation 2013, 96, 573-578. [CrossRef]

100. Tollemar, J.; Höckerstedt, K.; Ericzon, B.G.; Jalanko, H.; Ringdén, O. Prophylaxis with liposomal amphotericin B (AmBisome) prevents fungal infections in liver transplant recipients: Long-term results of a randomized, placebo-controlled trial. Transplant. Proc. 1995, 27, 1195-1198. [PubMed]

101. Jorgenson, M.R.; Descourouez, J.L.; Marka, N.A.; Leverson, G.E.; Smith, J.A.; Andes, D.R.; Fernandez, L.A.; Foley, D.P. A targeted fungal prophylaxis protocol with static dosed fluconazole significantly reduces invasive fungal infection after liver transplantation. Transpl. Infect. Dis. 2019, 21, e13156. [CrossRef]

102. Husain, S.; Camargo, J.F. Invasive Aspergillosis in solid-organ transplant recipients: Guidelines from the American Society of Transplantation Infectious Diseases Community of Practice. Clin. Transplant. 2019, 33, e13544. [CrossRef] [PubMed]

103. Neyra, K.M.; Brizendine, K.D. Retrospective study evaluating the performance of risk factors for invasive mold infections in liver transplantation. Transpl. Infect. Dis. 2019, 22, e13223. [CrossRef] [PubMed]

104. Kang, W.-H.; Song, G.-W.; Lee, S.-G.; Suh, K.-S.; Lee, K.-W.; Yi, N.-J.; Joh, J.W.; Kwon, C.H.D.; Kim, J.M.; Choi, D.L.; et al. A Multicenter, Randomized, Open-Label Study to Compare Micafungin with Fluconazole in the Prophylaxis of Invasive Fungal Infections in Living-Donor Liver Transplant Recipients. J. Gastrointest. Surg. 2019, 24, 832-840. [CrossRef]

105. Winston, D.; Limaye, A.; Pelletier, S.; Safdar, N.; Morris, M.; Meneses, K.; Busuttil, R.; Singh, N. Randomized, Double-Blind Trial of Anidulafungin Versus Fluconazole for Prophylaxis of Invasive Fungal Infections in High-Risk Liver Transplant Recipients. Arab. Archaeol. Epigr. 2014, 14, 2758-2764. [CrossRef] [PubMed]

106. Chakravarti, A.; Butler-Laporte, G.; Carrier, F.M.; Bilodeau, M.; Huard, G.; Corsilli, D.; Savard, P.; Luong, M. Targeted caspofungin prophylaxis for invasive aspergillosis in high-risk liver transplant recipients, a single-center experience. Transpl. Infect. Dis. 2021, e13568. [CrossRef]

107. Balogh, J.; Burroughs, S.G.; Boktour, M.; Patel, S.; Saharia, A.; Ochoa, R.A.; McFadden, R.; Victor, D.W.; Ankoma-Sey, V.; Galati, J.; et al. Efficacy and cost-effectiveness of voriconazole prophylaxis for prevention of invasive aspergillosis in high-risk liver transplant recipients. Liver Transplant. 2015, 22, 163-170. [CrossRef]

108. Amin, A.; Molina, A.; Quach, L.; Ito, T.; McMillan, R.; DiNorcia, J.; Agopian, V.G.; Kaldas, F.M.; Farmer, D.G.; Busuttil, R.W.; et al. Liver Transplantation in Patients With Pretransplant Aspergillus Colonization: Is It Safe to Proceed? Transplantation 2021, 105, 586-592. [CrossRef] 